\title{
Lab-to-clinic application of stem cell therapy for stroke
}

\author{
Mia C. Borlongan ${ }^{1,2^{*}}$, Sonya Kong ${ }^{1,2}$ and David C. Hess ${ }^{3}$
}

\begin{abstract}
Stem cell therapy or "cell therapy" has been demonstrated to be a potent treatment intervention in animal models of acute ischemic stroke, and recently has been introduced as an experimental therapy in early phase clinical trials. Among the many stem cells, the bone marrow adherent cell type known as mesenchymal stem cells have emerged in laboratory studies as a safe and effective therapy for ischemic stroke and other brain diseases. In particular, a unique population of adherent bone marrow-derived cells, called MultiStem cells, display immunomodulatory effects and are a promising allogeneic cell therapy in acute ischemic stroke. Here, we describe the preclinical evidence supporting the use of MultiStem in the acute setting of ischemic stroke and the translation into an early phase clinical trial in ischemic stroke.
\end{abstract}

Keywords: Multistem, Cerebral ischemia, Preclinical, Clinical, Translational

\section{Background}

Stroke is still a primary cause of mortality and morbidity in developed countries [1, 2]. Despite the advent of thrombolytic therapy as a stroke treatment, the limited therapeutic window only benefits a small number of stroke patients. Of note, tissue plasminogen activator (tPA), which is the only approved drug by US Food \& Drug Administration, needs to be administered to ischemic stroke patients within three hours [3]. Even those who receive such thrombolytic treatment display significant disability following 3 months of stroke onset. In accordance with the ECASS 3 trial and the American Stroke Association advisory panel, the window for treatment has been extended to 4.5-hours. However, despite the expansion of the tPA treatment time window, many stroke patients are still left with significant disability $[4,5]$. Endovascular thrombectomy (ET) is also effective in acute ischemic stroke; however it must be started within $6 \mathrm{~h}$ of stroke onset, less than $5-10 \%$ of stroke patients are eligible for treatment, and more than $50 \%$ remain with significant disability after ET [6]. It is,

\footnotetext{
* Correspondence: mborlong@berkeley.edu

${ }^{1}$ Center of Excellence for Aging and Brain Repair, Morsani College of

Medicine, University of South Florida, 12901 Bruce B. Downs Blvd., Tampa, FL 33612, USA

${ }^{2}$ Research Service at James Haley VA Hospital, Tampa, FL 33612, USA Full list of author information is available at the end of the article
}

therefore, essential to develop a neurorestorative and neuroreparative treatment for ischemic stroke that could be administered at a later time window since the current time window of 3-6 h limits the number of stroke patients whom can benefit $[1,2]$.

Cell therapy represents a treatment option for a wider therapeutic time window in stroke patients by targeting multiple reparative, anti-inflammatory, and cytoprotective processes $[6,7]$ The cells can be administered through intracerebral, intrathecal, intra-arterial, or intravenous (IV) settings. Since the IV route is available in the community hospital setting, it is the most feasible method of administration and the most likely to be disseminated throughout the healthcare system. Despite the belief that the IV route may not provide sufficient cells to the brain due to the distribution to peripheral organs, cells that get lodged into the lung and spleen appear to contribute to the overall benefit from cell therapy. For example, after IV delivery of MSCs, there is an improvement in cardiac performance and reduction of myocardial damage as the lungs trap MSCs and secrete the anti-inflammatory factor, alpha inducible protein (TNFA1P6, or TSG-6) [7, 8]. Similarly, if hematopoietic stem cells and human umbilical cord blood stem cells are delivered intravenously after stroke [8-10], there is reduction in the transmigration of splenocytes, counteracting both the acute inflammatory injury to the brain and the later stroke-induced shrinking 
and "exhaustion" of the spleen that makes the patient more vulnerable to infection [9-13]. Therefore, there may be advantages to IV delivery versus the intracerebral or intra-arterial methods.

The optimal time window for IV administration is inconclusive, but it may extend out as far as 30 days after the ischemic stroke [12, 14]. Specifically, the early, 'tail end' of the neuroprotective period in the time period of about $24 \mathrm{~h}$, presents a rich array of therapeutic targets and an active period of brain remodeling that could be exploited to salvage penumbral tissue and alter inflammatory and immune responses, still evolving days to weeks after the initial stroke $[1,2,7]$.

\section{Finding an effective and safe stem cell therapy for stroke}

Progenitor stem cells derived from bone marrow or placental tissue are advantageous in cell therapy because they pose no ethical problems or concerns and few safety concerns. Specifically, MSCs serve as a promising form of cell therapy due to their anti-inflammatory and immunomodulatory properties that permit the cells to be transplanted in genetically dissimilar tissue [13-16]. This could lead to cell manufacture of allogeneic cells from healthy unrelated donors (as opposed to autologous cells), allowing a scalable and 'off the shelf' stem cell product, that requires no tissue matching.

MAPCs, originally discovered by Verfaillie et al. [15-19] are a distinct adherent bone marrow population that are able to differentiate into cells from all three varying germ layers. After blastocyst injection, their multipotent nature was confirmed by the presence of the cells in all tissues. MAPCs can be isolated from either human or rodent bone marrow, and the cells' highly expandable nature allows for the cells to be cryopreserved over extended periods and subsequently thawed for clinical use $[15,19]$. Early studies showed the cells were effective in a rodent stroke model; intracerebral transplantation of MAPC one-week after cortical stroke resulted in the cells displaying a trophic effect on the host brain that improved sensorimotor ability $[18,20]$.

Athersys, Inc. has developed a clinical grade scale cell therapy product called MultiStem [21] based on Verfaillie et al. isolation procedure of MAPCs [15-19]. Multiple preclinical studies investigating MultiStem's administration have provided insights into the cells' mechanisms of action, including neurotrophic and/or neuroprotective improvements in animal models with neonatal hypoxicischemic encephalopathy or focal ischemia [20-25] as well as significant reduction in inflammatory cascades and immune modulation in rodents with traumatic brain injury and spinal cord injury [23, 24, 26-28].

There are many advantages of MultiStem for cell therapy compared with other stem cells. In accordance with
Good Manufacturing Practice (GMP) conditions, MultiStem have the potential to be manufactured in large scale and in uniform clinical doses. Similarly, the nature in which the MultiStem cells can be cryopreserved and its subsequent use as an allogeneic product without matching tissues, as noted by the preclinical research completed by Athersys, would allow for easy distribution to patients at appropriate times and dosages $[19,21]$. MultiStem cells suppress mixed lymphocyte reactions involving allogeneic $\mathrm{T}$ cells and peripheral blood cells and are non-immunogenic [25, 29]. Similarly, in a rat ischemic stroke model, MultiStem cells derived from either rats or humans, when transplanted allogeneic and xenogeneic cells, respectively, exhibited comparable level of functional recovery without the use of immunosuppression [22].

In focal cerebral ischemia, MultiStem cells' mechanism of action is rooted in trophic and immunomodulatory actions $[26,27,30,31]$. While human MAPCs cause a reduction in axonal dieback and the secretion of matrix metalloproteinase 9 (MMP-9), there is also a shift from the pro-inflammatory state of M1 to an anti-inflammatory, 'alternatively activated' state of M2 in an in vitro axonal dieback and an adult rat dorsal column crush model $[23,26]$. MAPCs are also effective at improving ischemic limb function and preservation when delivered directly into the tissue as observed in a model of limb ischemia $[24,32]$. Moreover, IV-administered MAPCs preserve splenic mass when they migrate to the spleen and prevent the increase in blood brain barrier permeability as shown in a rodent model of traumatic brain injury [28]. A distinct phenotypic feature of MAPCs over MSCs is their ability to differentiate into endothelial cells and smooth muscles $[28,29,32,33]$. as well as their capability to secrete vascular endothelial growth factor (VEGF) and other angiogenic molecules in vitro, and to increase vascular density in vivo in a myocardial infarction model [30, 34].

\section{Translation to the bedside}

MultiStem cell-based therapy is a promising therapeutic avenue for ischemic stroke. In acute myocardial infarction and in prophylaxis of graft vs. host disease, MultiStem cells have completed early phase clinical trials. MultiStem cells that were administered in myocardium after coronary intervention were well tolerated in a phase I trial of patients with first ST-elevation [31, 35]. There was improvement in stroke volume 4 to 12 months after patients were treated with a dose of about 50 million cells [31]. The MultiStem in Acute Stroke Treatment to Enhance Recovery Study (MASTERS) is a multicenter, randomized, double-blind, placebo-controlled trial of MultiStem in acute ischemic stroke where MultiStem are administered IV 24 to $48 \mathrm{~h}$ in moderate to moderatesevere ischemic stroke patients [36]. ClinicalTrials.gov 
Identifier: NCT01436487. This trial demonstrated the feasibility of administering a very large dose of cells IV -1.2 billion per patient- a much higher dose than can be achieved with other types of cell therapy. The study just completed enrollment. Careful and rigorous preclinical studies and limited clinical trials of MultiStem cells will provide guidance into the safe and effective application of cell therapy for stroke.

\section{Conclusion}

MultiStem are a promising cell therapy for ischemic stroke. Their major mechanism of action is likely immunomodulatory and they target the spleen and immune system. Clinical trials to date show safety of MultStem. The major advantages of clinical grade MultiStem are scalability and "off the shelf" availability in a hospital pharmacy with no requirement for tissue matching. If shown effective in ongoing and future clinical trials in ischemic stroke, MultiStem would have a wider time window allowing more patients to benefit and would also be available not only in academic medical centers but also in community hospitals.

\section{Abbreviations \\ ET: Endovascular thrombectomy; GMP: Good Manufacturing Practice; IV: Intravenous; MASTERS: MultiStem in Acute Stroke Treatment to Enhance Recovery Study; MMP-9: Matrix metalloproteinase 9; NFA1P6 or TSG-6: Alpha inducible protein; tPA: Tissue plasminogen activator; VEGF: Vascular endothelial growth factor}

\section{Acknowledgement \\ The authors thank Sydney Corey, Shaila Ghanekar, and Jake Sokol for excellent technical assistance in the final preparation of this manuscript.}

\section{Funding}

Not applicable.

\section{Availability of data and materials}

This paper is a review article. Referred literature in this paper has been listed in the references part. The datasets supporting the conclusions of this article are available online by searching the PubMed. Some original points in this article come from the laboratory practice in our research centers and the authors' experiences.

\section{Authors' contributions}

The authors contributed equally to the conceptualization and write-up of this manuscript. All authors read and approved the final manuscript.

\section{Competing interests}

David C Hess maintains research contracts with Athersys, Inc and enrolls patients in the clinical trial.

\section{Consent for publication}

All authors approved the publication of this manuscript.

\section{Ethics approval and consent to participate}

Not applicable.

\section{Author details}

${ }^{1}$ Center of Excellence for Aging and Brain Repair, Morsani College of Medicine, University of South Florida, 12901 Bruce B. Downs Blvd., Tampa, FL 33612, USA. ${ }^{2}$ Research Service at James Haley VA Hospital, Tampa, FL 33612, USA. ${ }^{3}$ Department of Neurology, Medical College of Georgia, Augusta University, 1120 15th Street, Augusta, GA 30912, USA.
Received: 14 July 2016 Accepted: 12 September 2016

Published online: 03 October 2016

\section{References}

1. Savitz SI, Cramer SC, Wechsler L, Consortium S. Stem cells as an emerging paradigm in stroke 3: enhancing the development of clinical trials. Stroke. 2014:45:634-9

2. Albers GW, Goldstein LB, Hess DC, et al. Stroke Treatment Academic Industry Roundtable (STAIR) recommendations for maximizing the use of intravenous thrombolytics and expanding treatment options with intraarterial and neuroprotective therapies. Stroke. 2011:42:2645-50.

3. Tissue plasminogen activator for acute ischemic stroke. The National Institute of Neurological Disorders and Stroke rt-PA Stroke Study Group. N Engl J Med 1995;333:1581-7

4. Hacke W, Kaste M, Bluhmki E, et al. Thrombolysis with alteplase 3 to 4 . 5 hours after acute ischemic stroke. N Engl J Med. 2008;359:1317-29.

5. Del Zoppo GJ, Saver JL, Jauch EC, Adams Jr HP, American Heart Association Stroke C. Expansion of the time window for treatment of acute ischemic stroke with intravenous tissue plasminogen activator: a science advisory from the American Heart Association/American Stroke Association. Stroke. 2009;40:2945.

6. Goyal M, Menon BK, van Zwam WH, et al. Endovascular thrombectomy after large-vessel ischaemic stroke: a meta-analysis of individual patient data from five randomised trials. Lancet. 2016:387(10029):1723-31.

7. Hess DC, Hill WD. Cell therapy for ischaemic stroke. Cell Prolif. 2011:44 Suppl 1:1-8.

8. Lee RH, Pulin AA, Seo MJ, et al. Intravenous hMSCs improve myocardial infarction in mice because cells embolized in lung are activated to secrete the anti-inflammatory protein TSG-6. Cell Stem Cell. 2009;5:54-63.

9. Schwarting S, Litwak S, Hao W, Bahr M, Weise J, Neumann H. Hematopoietic stem cells reduce postischemic inflammation and ameliorate ischemic brain injury. Stroke. 2008;39:2867-75.

10. Vendrame M, Gemma C, Pennypacker KR, et al. Cord blood rescues stroke-induced changes in splenocyte phenotype and function. Exp Neurol. 2006:199:191-200.

11. Offner $H$, Subramanian S, Parker SM, Afentoulis ME, Vandenbark AA, Hurn PD. Experimental stroke induces massive, rapid activation of the peripheral immune system. J Cereb Blood Flow Metab. 2006;26:654-65.

12. Offner $H$, Subramanian $S$, Parker SM, et al. Splenic atrophy in experimental stroke is accompanied by increased regulatory $T$ cells and circulating macrophages. J Immunol. 2006;176:6523-31.

13. Pennypacker KR, Offner $\mathrm{H}$. The role of the spleen in ischemic stroke. J Cereb Blood Flow Metab. 2015;35:186-7.

14. Shen $L H, L i Y, C$, Chen J, et al. Therapeutic benefit of bone marrow stromal cells administered 1 month after stroke. J Cereb Blood Flow Metab. 2007;27:6-13.

15. Beyth S, Borovsky Z, Mevorach D, et al. Human mesenchymal stem cells alter antigen-presenting cell maturation and induce T-cell unresponsiveness. Blood. 2005;105:2214-9.

16. Aggarwal S, Pittenger MF. Human mesenchymal stem cells modulate allogeneic immune cell responses. Blood. 2005;105:1815-22.

17. Jiang Y, Henderson D, Blackstad M, Chen A, Miller RF, Verfaillie CM. Neuroectodermal differentiation from mouse multipotent adult progenitor cells. Proc Natl Acad Sci U S A. 2003;100 Suppl 1:11854-60.

18. Jiang $Y$, Jahagirdar $B N$, Reinhardt $R L$, et al. Pluripotency of mesenchymal stem cells derived from adult marrow. Nature. 2002;418:41-9.

19. Jiang Y, Vaessen B, Lenvik T, Blackstad M, Reyes M, Verfaillie CM. Multipotent progenitor cells can be isolated from postnatal murine bone marrow, muscle, and brain. Exp Hematol. 2002;30:896-904.

20. Zhao LR, Duan WM, Reyes M, Keene CD, Verfaillie CM, Low WC. Human bone marrow stem cells exhibit neural phenotypes and ameliorate neurological deficits after grafting into the ischemic brain of rats. Exp Neurol. 2002;174:11-20.

21. Van Bokkelen G. Company profile: Athersys. Regen Med. 2011;6:39-43.

22. Mays RW, Borlongan CV, Yasuhara T, Hara K, Maki M, Carroll JE, Deans RT, Hess DC. Development of an allogeneic adherent stem cell therapy for treatment of ischemic stroke. J Exp Stroke Transl Med. 2010;3:34-46.

23. Tang Y, Yasuhara T, Hara K, et al. Transplantation of bone marrow-derived stem cells: a promising therapy for stroke. Cell Transplant. 2007;16:159-69.

24. Yasuhara T, Hara K, Maki M, et al. Intravenous grafts recapitulate the neurorestoration afforded by intracerebrally delivered multipotent adult 
progenitor cells in neonatal hypoxic-ischemic rats. J Cereb Blood Flow Metab. 2008;28:1804-10.

25. Yasuhara T, Matsukawa N, Yu G, et al. Transplantation of cryopreserved human bone marrow-derived multipotent adult progenitor cells for neonatal hypoxic-ischemic injury: targeting the hippocampus. Rev Neurosci. 2006;17:215-25.

26. Busch SA, Hamilton JA, Horn KP, et al. Multipotent adult progenitor cells prevent macrophage-mediated axonal dieback and promote regrowth after spinal cord injury. J Neurosci. 2011;31:944-53.

27. DePaul MA, Palmer M, Lang BT, et al. Intravenous multipotent adult progenitor cell treatment decreases inflammation leading to functional recovery following spinal cord injury. Sci Rep. 2015;5:16795.

28. Walker PA, Shah SK, Jimenez F, et al. Intravenous multipotent adult progenitor cell therapy for traumatic brain injury: preserving the blood brain barrier via an interaction with splenocytes. Exp Neurol. 2010;225:341-52.

29. Kovacsovics-Bankowski M, Streeter PR, Mauch KA, et al. Clinical scale expanded adult pluripotent stem cells prevent graft-versus-host disease. Cell Immunol. 2009;255:55-60.

30. Mays RW, van't Hof W, Ting AE, Perry R, Deans R. Development of adult pluripotent stem cell therapies for ischemic injury and disease. Expert Opin Biol Ther. 2007;7:173-84.

31. Ting AE, Mays RW, Frey MR, Hof WW, Medicetty S, Deans R. Therapeutic pathways of adult stem cell repair. Crit Rev Oncol Hematol. 2008;65:81-93.

32. Aranguren $\mathrm{XL}$, McCue JD, Hendrickx B, et al. Multipotent adult progenitor cells sustain function of ischemic limbs in mice. J Clin Invest. 2008;1 18:505-14.

33. Aranguren $\mathrm{XL}$, Luttun $\mathrm{A}$, Clavel $\mathrm{C}$, et al. In vitro and in vivo arterial differentiation of human multipotent adult progenitor cells. Blood. 2007:109:2634-42.

34. Van't Hof W, Mal N, Huang Y, et al. Direct delivery of syngeneic and allogeneic large-scale expanded multipotent adult progenitor cells improves cardiac function after myocardial infarct. Cytotherapy. 2007;9:477-87.

35. Penn MS, Ellis S, Gandhi S, et al. Adventitial delivery of an allogeneic bone marrow-derived adherent stem cell in acute myocardial infarction: phase I clinical study. Circ Res. 2012;110:304-11.

36. Hess DC, Sila CA, Furlan AJ, Wechsler LR, Switzer JA, Mays RW. A double-blind placebo-controlled clinical evaluation of MultiStem for the treatment of ischemic stroke. Int J Stroke. 2014;9:381-6.

\section{Submit your next manuscript to BioMed Central and we will help you at every step:}

- We accept pre-submission inquiries

- Our selector tool helps you to find the most relevant journal

- We provide round the clock customer support

- Convenient online submission

- Thorough peer review

- Inclusion in PubMed and all major indexing services

- Maximum visibility for your research

Submit your manuscript at www.biomedcentral.com/submit

) Biomed Central 